\title{
Keuzeonderwijs tandheelkunde in Groningen: een analyse van de operationalisatie van kerndoelen en het bereik ervan
}

\author{
H.M.J. Raghoebar-Krieger, J. Tams, W.M. Molenaar, M.C.D.N.J.M. Huysmans
}

\section{Samenvatting}

Inleiding: In de tandartsopleiding in Groningen krijgen specifieke onderwerpen vorm in keuzeprojecten. Om na te gaan of deze keuzeprojecten een bijdrage leveren aan de eisen die er voor de tandartsopleiding gesteld zijn, wordt bestudeerd of de verschillende keuzeprojecten een programma realiseren conform de beoogde doelen. Tevens wordt onderzocht of deze doelen worden bereikt volgens studenten.

Methode: De programmabeschrijvingen van alle keuzeprojecten $(n=11)$ zijn geanalyseerd door een expert aan de hand van een vragenlijst. Deze vragenlijst werd ook gebruikt om de mening van studenten ( $n=96)$ te inventariseren.

Resultaten: Uit de programmabeschrijvingen blijkt dat vier doelen (kennis en inzicht; theorie en praktijk; antwoorden funderen met literatuur; literatuur verwerken in opdrachten) in alle keuzeprojecten gerealiseerd worden. Twee doelen (verduidelijking beroepsbeeld; aanzet tot differentiatie/specialisatie) worden in respectievelijk tien en vier keuzeprojecten gerealiseerd en één doel (zoeken naar literatuur) komt helemaal niet aan de orde. Studenten vinden dat zij de volgende doelen bereiken: kennis en inzicht (94\%); theorie en praktijk (82\%); verduidelijking beroepsbeeld (77\%); aanzet tot differentiatie/specialisatie (46\%); zoeken naar literatuur (38\%); antwoorden funderen met literatuur(52\%); literatuur verwerken in opdrachten (77\%).

Discussie/conclusies: De keuzeprojecten leveren een bijdrage aan de eisen die er voor de tandartsopleiding gesteld zijn, doordat een groot deel van de beoogde doelen gerealiseerd wordt in de programmabeschrijvingen. Echter, studenten geven aan maar een deel van de doelen te behalen. Meer aandacht voor de specialisatie- en differentiatiefunctie en de wetenschappelijke oriëntatie van de keuzeprojecten is wenselijk. Uitbreiding van de doelen met de vorming van professioneel gedrag zou een verbetering kunnen zijn. (Raghoebar-Krieger HMJ, Tams J, Molenaar WM, Huysmans MCDNJM. Keuzeonderwijs tandheelkunde in Groningen: een analyse van de operationalisatie van kerndoelen en het bereik ervan. Tijdschrift voor Medisch Onderwijs 2006;25(1):14-21.)

\section{Inleiding}

In de tandartsopleiding in Groningen krijgen onderwerpen die niet of weinig in het kerncurriculum aan de orde komen, vorm in keuzeonderwijs (c.q. keuzeprojecten). De onderwerpen zijn zeer gevarieerd van aard en gericht op de tegenwoordige praktijk van de tandarts. Gezien de recente ontwikkelingen in de tandheelkundige zorgverlening in Nederland, wordt de tandarts-algemeen practicus steeds meer de spil van een tandheelkundig zorgteam. ${ }^{1-3}$ Hij richt zich, veel minder dan in het verleden, op de tandheelkundige basiszorg. Naast zijn werkzaamheden als manager van het totale pakket aan tandheelkundige zorg binnen zijn tandheelkundig team, kan de tandarts zich toeleggen op een zelf gekozen onderdeel van de zorg. Enkele van deze onderdelen worden in de tandartsopleiding aangeboden in keuzeonderwijs. 
Keuzeonderwijs biedt de studenten de gelegenheid dieper en geconcentreerder in te gaan op tandheelkundige onderwerpen; studenten kiezen het onderwerp waartoe zij zich het meest aangetrokken voelen. Hiermee appelleert het keuzeonderwijs aan een centrale doelstelling van de tandheelkundeopleiding, namelijk: de verantwoordelijkheid van de student voor zijn/haar eigen individuele leerweg. Dit betekent o.a. dat studenten het keuzeonderwijs in jaar 4 zeer gevarieerd mogen invullen. Er kan bijvoorbeeld onderwijs gevolgd worden bij andere faculteiten (algemeen vormende vakken), en ook bij de geneeskundeopleiding. Daarnaast kan de student het programma individueel invullen en het gebruiken als een verlenging van de wetenschappelijke stage (of het combineren met een buitenlandse stage). Verder is het keuzeonderwijs onderdeel van het wetenschappelijk programma van de hele opleiding, doordat het een oriëntatie biedt op de wetenschappelijke aspecten van de tandheelkunde.

Het keuzeonderwijs is een verplicht onderdeel van het programma gedurende de laatste twee jaren van de opleiding, waarbij in het vierde studiejaar het onderwijs in een preklinische setting plaatsvindt. In jaar 5 staat het onderwijs in de kliniek centraal. De tijd die studenten krijgen om de keuzeprojecten te volgen is in jaar 4 en 5 respectievelijk vier en acht weken. Deze tijd wordt, afhankelijk van het keuzeproject, verspreid over een aantal weken of maanden. De keuzeprojecten worden gehonoreerd met 1 tot 4 studiepunten (1 studiepunt=40 uur).

De keuzeprojecten zijn gericht op de volgende kerndoelen: een theoretische en (pre)klinische verdieping van en een orientatie op de wetenschappelijke aspecten van de tandheelkunde. Doelen vervullen in het onderwijs een wezenlijke functie, omdat zij richtinggevend zijn voor veel beslissingen die moeten uitmonden in een verantwoord en hanteerbaar werkplan voor o.a. de inhoud van het programma, onderwijsvormen, docentrollen, toetsing en de evaluatie van onderwijs. ${ }^{4-5}$ Echter, doelen worden vaak algemeen opgesteld en liggen daardoor op een hoog abstractieniveau. Er wordt niet in specifieke termen omschreven wat men aan de student wil leren. ${ }^{6-7}$ Hierdoor is de kans groot dat er een onderwijssituatie ontstaat die niet eenduidig is; de docent kan vele kanten uit en kan altijd rechtvaardigen dat zijn of haar onderwijs vanuit de doelen gestuurd wordt. Concrete doelen, daarentegen, zijn eenduidig en gemakkelijk om te zetten in opdrachten voor studenten. ${ }^{4}$

Omdat de drie kerndoelen voor het keuzeonderwijs toch vrij algemeen zijn geformuleerd, is de kans groot dat er ook hier geen eenduidige onderwijsleersituatie is. Daar het keuzeonderwijs een bijdrage moet leveren aan de eisen die er voor de tandartsopleiding in Groningen zijn gesteld, ${ }^{8-9}$ is het dus relevant om na te gaan in hoeverre de verschillende keuzeprojecten een programma realiseren conform de kerndoelen van het keuzeonderwijs. Een logische stap is vervolgens na te gaan of de doelen bereikt worden volgens de studenten. De centrale vragen in dit onderzoek zijn:

1. Zijn de kerndoelen van het keuzeonderwijs op eenduidige wijze geoperationaliseerd c.q. geconcretiseerd in de afzonderlijke keuzeprojecten?

2. Bereiken studenten de beoogde kerndoelen?

\section{Methode}

\section{Onderzoeksopzet}

Het onderzoek is uitgevoerd aan de hand van een analyse van de programmabeschrijvingen voor de keuzeprojecten van het jaar 2002/2003. Daarnaast zijn vierdeen vijfdejaarsstudenten tandheelkunde 
van de Faculteit der Medische Wetenschappen, Rijksuniversiteit Groningen (FMW/RuG) in het studiejaar 2002/2003 in het onderzoek betrokken. Zowel de gegevens uit de analyse van de programmabeschrijvingen als de gegevens van de studenten hebben betrekking op de keuzeprojecten van jaar 4 (Adhesieve/esthetische tandheelkunde met plastische materialen; Hoofd-hals pathologie; Implantologie; Mondzorg voor bijzondere groepen; Intra-orale reparatietechnieken) en jaar 5 (Gemutileerde dentitie; Esthetische tandheelkunde; Orthodontie; Implantologie; Kindertandheelkunde; Mondzorg voor bijzondere groepen).

Om vast te stellen of de kerndoelen op eenduidige wijze zijn geoperationaliseerd in de keuzeprojecten, zijn de voor studenten beschikbare programmabeschrijvingen van bovengenoemde keuzeprojecten $(n=11)$ verzameld en geanalyseerd. Om vast te stellen of studenten vinden dat zij de kerndoelen van de keuzeprojecten halen, zijn alle studenten uit jaar $4(n=43)$ en jaar $5(n=53)$ die keuzeprojecten volgden aan het eind van het keuzeproject benaderd om een vragenlijst in te vullen.

\section{Instrument}

Voor het beantwoorden van beide onderzoeksvragen is een vragenlijst gebruikt die bestaat uit drie onderdelen (gebaseerd op de drie kerndoelen), namelijk: theoretische verdieping, (pre)klinische verdieping, wetenschappelijke oriëntatie. Bij elk

Tabel 1 Vragenlijst (3 onderdelen en bijbehorende variabelen).

\begin{tabular}{|c|c|c|}
\hline & $\begin{array}{l}\text { T.b.v. de analyse van de } \\
\text { programmabeschrijvingen }\end{array}$ & T.b.v. de mening van studenten \\
\hline $\begin{array}{l}\text { Theoretische } \\
\text { kennis }\end{array}$ & $\begin{array}{l}\text { Bevat de programmabeschrijving } \\
\text { doelstellingen over kennis en inzicht } \\
\text { die niet of weinig in het kerncurriculum } \\
\text { voorkomen? }\end{array}$ & $\begin{array}{l}\text { Het keuzeproject heeft bijgedragen aan } \\
\text { meer kennis en inzicht over een bepaald } \\
\text { onderwerp. }\end{array}$ \\
\hline \multirow[t]{3}{*}{$\begin{array}{l}\text { Preklinische } \\
\text { verdieping }\end{array}$} & $\begin{array}{l}\text { Laat de programmabeschrijving zien } \\
\text { dat er een goed evenwicht is tussen } \\
\text { theorie en praktijk? }\end{array}$ & $\begin{array}{l}\text { In het keuzeproject was er een goed } \\
\text { evenwicht tussen theorie en praktijk. }\end{array}$ \\
\hline & $\begin{array}{l}\text { Laat de programmabeschrijving zien } \\
\text { dat er een bijdrage wordt geleverd } \\
\text { aan de oriëntatie op het beroep van } \\
\text { tandarts? }\end{array}$ & $\begin{array}{l}\text { Dit keuzeproject heeft het beroepsbeeld } \\
\text { van tandarts voor mij verduidelijkt. }\end{array}$ \\
\hline & $\begin{array}{l}\text { Laat de programmabeschrijving zien } \\
\text { dat er aandacht wordt besteed aan de } \\
\text { differentiaties en specialisaties binnen } \\
\text { de tandheelkunde? }\end{array}$ & $\begin{array}{l}\text { Dit keuzeproject is een aanzet geweest } \\
\text { tot differentiatie/specialisatie. }\end{array}$ \\
\hline \multirow[t]{3}{*}{$\begin{array}{l}\text { Wetenschappelijke } \\
\text { oriëntatie }\end{array}$} & $\begin{array}{l}\text { Laat de programmabeschrijving zien } \\
\text { dat de student leert zoeken naar } \\
\text { literatuur met betrekking tot een } \\
\text { specifiek probleem? }\end{array}$ & $\begin{array}{l}\text { Ik heb systematisch leren zoeken naar } \\
\text { literatuur met betrekking tot een } \\
\text { specifiek probleem. }\end{array}$ \\
\hline & $\begin{array}{l}\text { Laat de programmabeschrijving } \\
\text { zien dat de student leert om met } \\
\text { behulp van literatuurbevindingen een } \\
\text { gefundeerd antwoord te geven op een } \\
\text { vraag? }\end{array}$ & $\begin{array}{l}\text { Ik heb geleerd om met behulp van de } \\
\text { literatuurbevindingen een gefundeerd } \\
\text { antwoord te geven op een vraag. }\end{array}$ \\
\hline & $\begin{array}{l}\text { Laat de programmabeschrijving zien } \\
\text { dat de literatuurbevindingen in een } \\
\text { werkstuk/opdracht verwerkt moeten } \\
\text { worden? }\end{array}$ & $\begin{array}{l}\text { Ik kon de literatuurbevindingen in een } \\
\text { werkstuk/opdracht verwerken. }\end{array}$ \\
\hline
\end{tabular}


onderdeel behoren een of meer variabelen, die in vraagvorm of als stelling zijn geformuleerd. De inhoud van de variabelen is identiek voor het beantwoorden van beide onderzoeksvragen; de wijze waarop ze gesteld zijn, verschilt wel (tabel 1).

De vragen voor de analyse van de programmabeschrijvingen werden kwalitatief beantwoord. De stellingen voor de studenten werden op een 4-puntsschaal beantwoord: $1=$ helemaal mee eens, $2=$ grotendeels mee eens, 3 = grotendeels niet mee eens, $4=$ helemaal niet mee eens. Indien de vraag niet van toepassing is, kan de student dit aangeven.

\section{Analyse}

Aan de hand van de vragenlijst heeft een expert (M.C.D.N.J.M. Huysmans) een inhoudsanalyse uitgevoerd van de programmabeschrijvingen. De inhoudsanalyse is een interpretatieve werkwijze, waarbij de reconstructie van de betekenis in het materiaal centraal staat. ${ }^{10}$ De expert is de coördinator van het keuzeonderwijs en tandarts. Zij heeft niet deelgenomen aan de totstandkoming van de programmabeschrijvingen.

De gegevens van studenten op de vragen zijn verwerkt door het berekenen van frequenties. De vier antwoordcategorieën zijn gedichotomiseerd tot 'eens' (score 1, 2) en 'oneens' (score 3, 4).

\section{Resultaten}

\section{Operationalisatie kerndoelen in programmabeschrijvingen}

Van alle keuzeprojecten $(n=11)$ waren programmabeschrijvingen beschikbaar. De resultaten uit de inhoudsanalyse laten zien dat het kerndoel met betrekking tot de theoretische kennis in alle keuzeprojecten geoperationaliseerd is in leerdoelen, die in toetsbare uitkomsten weergeven in welk onderwerp kennis en inzicht moeten wor- den opgedaan (tabel 2). Bij elk keuzeproject zijn minimaal vier en maximaal zeven leerdoelen geformuleerd. Daarbij maakt elk project een onderscheid in de onderwerpen die studenten moeten kennen (bv.: 'de student heeft kennis van de interactie tussen conditioneringsmethoden en substraten') en de vaardigheden die ze moeten beheersen (bv.: 'een student kan in een preklinische situatie reparatietechnieken indiceren en toepassen'). In sommige keuzeprojecten is er sprake van een verbreding, wat wil zeggen dat er onderwerpen aan de orde komen die eerder in het kerncurriculum niet zijn onderwezen (jaar 4: Hoofd-hals pathologie; Mondzorg voor bijzondere groepen; Intra-orale reparatietechnieken; jaar 5: Mondzorg voor bijzondere groepen). In andere keuzeprojecten wordt juist dieper ingegaan op onderwerpen die wel eerder in het kerncurriculum aan de orde zijn geweest (jaar 4: Adhesieve/esthetische tandheelkunde met plastische materialen; Implantologie; jaar 5: Gemutileerde dentitie; Esthetische tandheelkunde; Kindertandheelkunde). Twee keuzeprojecten die zowel ter verdieping als ter verbreding een functie hebben, zijn Orthodontie en Implantologie in jaar 5.

Het tweede kerndoel, (pre)klinische verdieping, wordt geoperationaliseerd door studenten afwisselend bezig te laten zijn met het bestuderen van leerstof en het werken in de (pre)kliniek. De verhouding theorie-kliniek komt in alle programmabeschrijvingen tot uiting. Het bestuderen van leerstof wordt gedaan in het kader van schriftelijke verslaglegging, mondelinge presentaties en uiteraard ook het uitvoeren van (pre)klinisch werk. In de prekliniek (jaar 4) moeten studenten ervaringen opdoen aan de hand van experimenten, het vervaardigen van preklinische werkstukken en/of laboratoriumwerk. In jaar 5 werken de studenten in de kliniek met patiënten, waarbij het opdoen van kennis, in- 
zicht in en ervaring met diagnostiek en de behandeling van patiënten voorop staat. In zowel jaar 4 als jaar 5 wordt hierdoor een bijdrage geleverd aan de oriëntatie op het beroep van tandarts en de differentiaties en specialisaties daarbinnen. Deze bijdrage is wel wisselend. In sommige keuzeprojecten is er meer sprake van een oriëntatie op het beroep van tandarts (jaar 4: Adhesieve tandheelkunde; Mondzorg voor bijzondere groepen; Intra-orale reparatie-technieken; jaar 5: Gemutileerde dentitie; Esthetische tandheelkunde; Mondzorg voor bijzondere groepen). In andere keuzeprojecten is er meer sprake van een differentiatie of specialisatie binnen de tandheelkunde (jaar 4: Implantologie; jaar 5 Orthodontie; Implantologie; Kindertandheelkunde). Het enige keuzeproject dat niet direct een oriëntatie biedt op het beroep van tandarts en de differentiaties en specialisaties daarbinnen, betreft een keuzeproject in jaar 4: Hoofdhals-pathologie (tabel 2).
Het derde kerndoel, wetenschappelijke oriëntatie, wordt gedeeltelijk geoperationaliseerd in de keuzeprojecten. Uit de programmabeschrijvingen kan worden afgeleid dat studenten de literatuur in alle keuzeprojecten van zowel jaar 4 als jaar 5 in de vorm van leerboeken en/of wetenschappelijke artikelen krijgen aangereikt. Er zijn geen gegevens in de programmabeschrijvingen dieeropwijzendatstudenten systematisch moeten zoeken naar literatuur over een specifiek onderwerp. Wel zijn er in de programmabeschrijvingen gegevens opgenomen waaruit blijkt dat studenten met behulp van literatuurbevindingen antwoorden moeten funderen. Zij moeten namelijk een schriftelijk verslag maken over een tandheelkundige probleemstelling en/of een presentatie houden. Dit moet gebeuren op basis van literatuur en ervaringen in de (pre)kliniek (tabel 2).

Tabel 2 Samenvatting oordeel expert.

\begin{tabular}{lc}
\hline & Oordeel expert* \\
\hline Meer kennis en inzicht & $\mathrm{n}=11$ \\
Goed evenwicht tussen theorie en praktijk & $\mathrm{n}=11$ \\
Verduidelijking beroepsbeeld tandarts & $\mathrm{n}=10$ \\
Aandacht voor differentiaties en specialisaties binnen het beroep? & $\mathrm{n}=4$ \\
Systematisch leren zoeken naar literatuur & $\mathrm{n}=0$ \\
Antwoorden funderen met behulp van literatuur & $\mathrm{n}=11$ \\
Literatuur verwerken in werkstuk/opdracht & $\mathrm{n}=11$ \\
\hline
\end{tabular}

* Aantal programmabeschrijvingen van de keuzeprojecten die de doelen realiseren.

Tabel 3 Percentage studenten dat meent de doelen bereikt te hebben.

\begin{tabular}{|c|c|c|}
\hline & $\begin{array}{c}\text { Jaar } 4 \\
(n=25)\end{array}$ & $\begin{array}{c}\text { Jaar } 5 \\
(n=41)\end{array}$ \\
\hline Meer kennis en inzicht & $100 \%$ & $88 \%$ \\
\hline Goed evenwicht tussen theorie en praktijk & $92 \%$ & $71 \%$ \\
\hline Verduidelijking beroepsbeeld tandarts & $76 \%$ & $78 \%$ \\
\hline Aanzet tot differentiatie/specialisatie & $36 \%$ & $56 \%$ \\
\hline Systematisch leren zoeken naar literatuur & $52 \%$ & $24 \%$ \\
\hline Antwoorden funderen met behulp van literatuur & $60 \%$ & $44 \%$ \\
\hline Literatuur verwerken in werkstuk/opdracht & $92 \%$ & $61 \%$ \\
\hline
\end{tabular}




\section{Bereik kerndoelen volgens studenten}

De vragenlijst is ingevuld door 25 vierdejaars- (58\%) en 41 vijdejaarsstudenten (77\%). Tabel 3 laat zien dat veel studenten (76\%-100\%) vinden dat zij de doelen over kennis en inzicht hebben verworven. Ditzelfde geldt voor de twee doelen behorende bij de preklinische verdieping. Minder tevreden zijn studenten (36\%-56\%) over het doelbereik als het gaat om de functie die keuzeprojecten zouden moeten hebben, namelijk het aanzetten tot differentiatie en specialisatie. De doelen betreffende de wetenschappelijke oriëntatie worden volgens $24 \%-92 \%$ van de studenten bereikt.

\section{Discussie}

De resultaten uit dit onderzoek tonen aan dat in de programmabeschrijvingen van de keuzeprojecten een groot deel van de kerndoelen gerealiseerd wordt. De kerndoelen zijn op een heldere wijze geoperationaliseerd in de elf verschillende programma's. Deze conclusie is gebaseerd op de resultaten van de inhoudsanalyse door een expert die niet onafhankelijk staat ten opzichte van het keuzeonderwijs, omdat zij tevens coördinator van het keuzeonderwijs is. Het is mogelijk dat dit gegeven tot een bias heeft geleid. Desalniettemin kan worden vastgesteld dat in alle keuzeprojecten eenduidig is weergegeven wat studenten moeten kennen en kunnen op het gebied van theorie, (pre)klinische verdieping en wetenschappelijke oriëntatie. Echter, niet alle aspecten met betrekking tot de wetenschappelijke oriëntatie krijgen even veel aandacht. Het gebruik van literatuur in werkstukken en het funderen van antwoorden met behulp van literatuur komt wel in elk keuzeproject aan de orde, maar het systematisch leren zoeken naar literatuur is in geen enkel programma onderdeel van het leerproces.

Het is logisch dat als er in een programma geen aandacht is voor een bepaald leerdoel, studenten dit ook niet zullen bereiken. Dit blijkt ook uit dit onderzoek: veel studenten geven inderdaad aan dat zij niet systematisch hebben leren zoeken naar literatuur. Opmerkelijk is dat er ook een aantal studenten is dat aangeeft dit doel wel te bereiken. Wellicht zijn - anders dan in de programmabeschrijving staat - in de keuzeprojecten toch enkele opdrachten gegeven om literatuur te zoeken. Daarentegen, de twee andere leerdoelen van de wetenschappelijke oriëntatie die volgens de programmabeschrijving wel aan de orde komen, antwoorden funderen en literatuur verwerken, worden maar door een deel van de studenten gehaald. Voor dit gegeven zijn er een aantal verklaringen.

Een eerste verklaring voor de mening van veel studenten dat zij niet systematisch hebben leren zoeken naar literatuur is het gegeven, dat zij in het wetenschappelijk programma van jaar 1, 2 en 3 al aan dit doel gewerkt hebben. ${ }^{11}$ Een andere verklaring blijkt uit de programmabeschrijvingen, namelijk: studenten krijgen in de keuzeprojecten literatuur aangereikt. Zij hoeven er dus niet zelf naar te zoeken. Een derde verklaring is wellicht de klinische praktijk waar het onderwijs in jaar 5 aan gebonden is. Studenten richten zich in jaar 5 vooral op de behandeling van patiënten, maar deze activiteit is vervolgens niet ingebed in zoekopdrachten naar literatuur. Tot slot kan de variabele 'systematisch leren zoeken naar literatuur' de oorzaak zijn van het lage percentage studenten dat dit doel beheerst. Deze variabele zou veranderd moeten worden, daar het niet van belang is te weten of studenten in het keuzeproject literatuur hebben leren zoeken, maar of ze daadwerkelijk gezocht hebben.

Daar wetenschappelijke oriëntatie een kerndoel is van het keuzeonderwijs, moet hier meer aandacht voor komen. Juist door 
de combinatie van theoretische opdrachten en praktisch werk in de (pre)kliniek zijn alle keuzeprojecten geschikt om het evidence-based handelen te oefenen. Docenten kunnen opdrachten koppelen aan de patiënt die de student behandelt. De opdrachten zouden studenten moeten uitdagen om wetenschappelijke overwegingen te betrekken bij de klinische besluitvorming in de praktijk. ${ }^{12}$

Een andere discrepantie tussen het programmadoel en het doelbereik bij studenten betreft de functie die keuzeprojecten beogen te hebben, namelijk een aanzet te zijn tot differentiatie en specialisatie. Het feit dat studenten vinden dat het keuzeproject geen aanzet is geweest voor differentiatie en specialisatie is wellicht te verklaren door de gegevens uit de inhoudsanalyse, die laten zien dat er onvoldoende nadruk ligt op dit onderwerp. Differentiatie en specialisatie verdienen daarom nadere aandacht. Wellicht kan onderzoek naar de samenhang tussen de keuze van studenten voor bepaalde onderwerpen in de opleiding en in post-academisch onderwijs nuttige informatie opleveren. Deze informatie kan dan gebruikt worden voor de inrichting van het keuzeonderwijs en een verbetering van de aansluiting met het postacademisch onderwijs. Binnen de basisartsopleiding heeft dergelijk onderzoek reeds plaatsgevonden. ${ }^{13}$ Hierbij is gekeken of de keuze van studenten voor een specifiek specialisme samenhangt met hun vervolgopleiding.

Bij het bestuderen van de programmabeschrijvingen is opgevallen dat de kerndoelen voornamelijk zijn geoperationaliseerd in aspecten van kennis en vaardigheden. Gedragsaspecten komen nauwelijks aan de orde, terwijl alle keuzeprojecten en met name die uit jaar 5 bij uitstek geschikt zijn om professioneel gedrag te beoordelen, omdat er in kleine groepen wordt gewerkt en de docent vrijwel alle studenten persoonlijk kent. Het vormen van professioneel gedrag wordt in toenemende mate belangrijk gevonden, ${ }^{8-9} 14 \mathrm{Om}$ deze reden wordt ook geadviseerd de kerndoelen van het keuzeonderwijs uit te breiden met dit onderwerp.

\section{Conclusies}

Het keuzeonderwijs levert een bijdrage aan de eisen die er voor de tandartsopleiding gesteld zijn, doordat een groot deel van de kerndoelen gerealiseerd wordt. Echter, studenten geven aan maar een deel van de doelen uit het programma te halen. Wil men de opbrengst van het keuzeonderwijs vergroten, dan is het aan te bevelen meer aandacht te geven aan:

1. de differentiatie- en specialisatiefunctie van de keuzeprojecten;

2. de wetenschappelijke oriëntatie, door met opdrachten te werken die een meer evidence-based karakter hebben. Daarnaast zouden de kerndoelen van het keuzeonderwijs uitgebreid moeten worden met het vormen van professioneel gedrag.

\section{Literatuur}

1. Bronkhorst EM. Menskrachtproblematiek in de tandheelkunde. Ned Tijdschr Tandheelkd 2001;108: 306-8.

2. Burgersdijk RCW, Kersten HW. De tandheelkundige opleiding en het teamconcept. Ned Tijdschr Tandheelkd 2001;108:319-22.

3. Corbey-Verheggen MJH. De mondhygiënist met uitgebreide bevoegdheden. Ned Tijdschr Tandheelkd 2001;108:323-5.

4. Corte E de, Geerligs CT, Lagerweij NAJ, Peters JJ, Vandenberghe R. Beknopte didaxologie. Groningen: Wolters-Noordhoff; 1981.

5. Groot AD de. Begrip van evalueren. 's Gravenhage: Vuga; 1986.

6. Bie D de. Doelen formuleren in het Onderwijs. 's Gravenhage: De Som; 1989.

7. Franssen HAM, Jager A, Rinkema-Kohlman VW. Denken over doelen: een literatuurstudie naar het inventariseren, formuleren en classificeren van onderwijsdoelstellingen als bijdrage aan de eindtermendiscussie. Utrecht: ISOR afdeling onderwijsonderzoek Rijksuniversiteit Utrecht; 1987. 
8. Rossum HJM van. Blauwdruk voor de opleiding Tandheelkunde te Groningen. Groningen: Faculteit der Medische Wetenschappen, Rijksuniversiteit Groningen; 2001.

9. Raamplan 2000 Tandartsopleiding. Eindtermen van de tandartsopleiding. Utrecht: VSNU; 2000.

10. Wester F. Strategieën voor kwalitatief onderzoek. Bussum: Coutinho; 1995.

11. Studiegids Tandheelkunde/Mondhygiëne2002/2003. Groningen: Onderwijsinstituut, Faculteit der Medische Wetenschappen; 2002.

12. Stegenga B. Wetenschappelijk denken en handelen. Projectplan voor de opleiding van de tandarts als academicus in T21. Groningen: Faculteit der Medische Wetenschappen, Rijksuniversiteit Groningen; 2004.

13. Molenaar WM, Reinders JJ, Cohen-Schotanus J. De relatie tussen specialisme van keuzeco-schap en vervolgopleiding. Tijdschrift voor Medisch Onderwijs 2004;23:23-9.

14. Professioneel gedrag. Onderwijs, toetsing, begeleiding en regelgeving. Eindrapport van het Projectteam Consilium Abeundi ingesteld door het DMW (VSNU). Eindrapport en bijlagen. Utrecht: [s.n.]; 2002.

\section{De auteurs:}

Mw. dr. H.M.J. Raghoebar-Krieger is als onderwijskundige verbonden aan het Onderwijsinstituut van het Universitair Medisch Centrum Groningen.

Dr. J. Tams is universitair hoofddocent Tandheelkunde en verbonden aan het Universitair Medisch Centrum Groningen

Mw. prof. dr. W.M. Molenaar is hoogleraar Medisch Onderwijs en verbonden aan het Onderwijsinstituut van het Universitair Medisch Centrum Groningen.

Mw. prof. dr. M.C.D.N.J.M. Huysmans is hoogleraar Conserverende Tandheelkunde en verbonden aan het Universitair Medisch Centrum Groningen.

\section{Correspondentieadres:}

Mw. dr. H.M.J. Raghoebar-Krieger, Onderwijsinstituut, Universitair Medisch Centrum Groningen, Rijksuniversiteit Groningen, A. Deusinglaan 1, 9713 AV Groningen, tel.: 050-3633105, fax: 050-3633865, h.m.j.raghoebarkrieger@med.umcg.nl.

\section{Summary}

Introduction: The Groningen Dental School offers several electives to its students. A study was performed to examine whether the elective programme is in line with the educational objectives of the dental curriculum. Students' perceptions of the match between electives and objectives were also sought.

Method: The programme descriptions of all electives $(n=11)$ were analysed by an expert using a questionnaire. This questionnaire was also used to survey students' opinions ( $n=96)$.

Results: The descriptions showed that the 4 goals (knowledge and understanding; theory and practice; underpinning answers with evidence from the literature; using the literature in assignments) were met by all the electives. Two objectives (insight into the work of a dental professional and stimulating differentiation/specialisation) were achieved by 10 and 4 electives, respectively and one objective (performing literature searches) was not included in any elective. The students indicated that the programme met the following objectives: knowledge and understanding (94\%); theory and practice (82\%); insight into the work of a dental professional (77\%); stimulating differentiation/specialisation (46\%); performing literature searches (38\%); underpinning answers with evidence from the literature (52\%); using the literature in assignments (77\%).

Discussion/conclusions: The electives were found to contribute to the educational objectives of the dental curriculum, because they met a considerable number of them. However, the students indicated that not all the objectives were met. More attention for differentiation and specialisation and the scientific orientation of the electives appears to be advisable. The programme could be improved by adding professional behaviour to the objectives. (Raghoebar-Krieger HMJ, Tams J, Molenaar WM, Huysmans MCDNJM. Electives in the Groningen dental curriculum: an analysis of the operationalisation and realisation of the core objectives. Dutch Journal of Medical Education 2006;25(1):14-21.) 